14.1

\title{
Спектральные характеристики питательной среды DMEM
}

\author{
() А.А. Жихорева, ${ }^{1,2}$ В.П. Белик, ${ }^{1}$ А.В. Белашов, ${ }^{1}$ О.С. Васютинский, ${ }^{1}$ И.м. Гаджиев, ${ }^{1}$ \\ С.Е. Гончаров, ${ }^{1}$ И.В. Семенова ${ }^{1, \uparrow}$ \\ ${ }^{1}$ Физико-технический институт им. А.Ф. Иоффре РАН, \\ 194021 Санкт-Петербург, Россия \\ 2 Университет ИТМО, \\ 197101 Санкт-Петербург, Россия \\ ๑ e-mail: irina.semenova@mail.ioffe.ru
}

(Поступило в Редакцию 1 февраля 2018 г.)

Представлены результаты исследования спектральных характеристик люминесценции питательной среды для культивирования клеток DMEM. Зарегистрирован спектр люминесценции среды в видимой и ближней ИК областях вплоть до $1350 \mathrm{~nm}$ при возбуждении на длинах волн 405 и $660 \mathrm{~nm}$. Определены времена жизни возбужденных состояний питательной среды и продемонстрировано отсутствие фосфоресценции синглетного кислорода в области вблизи $1270 \mathrm{~nm}$.

DOI: 10.21883/JTF.2018.09.46418.49-18

\section{Введение}

Клетки, культивируемые in vitro, широко используются в фундаментальных исследованиях по генетике и физиологии, молекулярной биологии и цитологии [1]. Одним из важнейших методов исследования биологических объектов является спектроскопия люминесценции, позволяющая исследовать разнообразные физико-химические процессы, а также получать люминесцентные изображения пространственных распределений различных маркеров: красителей, фотосенсибилизаторов [2], квантовых точек [3] и пр. в органеллах клеток с высоким пространственным разрешением, в том числе превышающим дифракционный предел [4]. Использование люминесцентных методов с разрешением во времени позволяет исследовать динамику внутриклеточных процессов и изучать механизмы воздействия различных агентов на внутриклеточные структуры. В частности, флуоресцентная микроскопия позволяет изучать динамику взаимодействия между белками, ДНК и РНК.

Для культивирования клеток in vitro используются питательные среды, которые содержат комплекс веществ, необходимых для обеспечения жизнеспособности, нормального развития и пролиферации клеток. Как правило, питательная среда содержит большой набор аминокислот, минеральных солей, витаминов, глюкозу, сыворотку в качестве источника факторов роста, гормоны и факторы адгезии [5]. Кроме того, питательная среда должна поддерживать необходимые значения $\mathrm{pH}$ и осмоляльности. Одной из наиболее широко используемых искусственных питательных сред для культивирования клеток является среда DMEM (Dulbecco's Modified Eagle Medium), которая используется для культивирования первичных и полуперевиваемых (диплоидных) клеток [6-8] и часто применяется для клеточных линий HeLa, 3T3 клон A31, COS-7 и др. [5].

При проведении исследований клеточных структур с применением люминесцентных методов необходимо иметь возможность отделять фон, связанный с возбуждением люминесценции питательной среды, в которой они инкубируются, от люминесценции собственно клеток. Поэтому спектральные и временные характеристики люминесценции питательной среды представляют большой интерес. В частности, данные о временах затухания люминесценции среды важны при проведении исследований методом FLIM (Fluorescence lifetime imaging microscopy), позволяющим строить изображения флуоресцентных меток в клеточных культурах на основе пространственных распределений времен затухания их флуоресценции [9].

В связи с активным развитием методов фотодинамической терапии, применяемых для лечения различных, в первую очередь онкологических заболеваний, значительная часть исследований посвящена реакции клеток in vitro на фотодинамическое воздействие с конкретными фотосенсибилизаторами при различных режимах воздействия. Обычно такие исследования ведутся с применением методов конфокальной флуоресцентной микроскопии [10], проточной цитофлуориметрии [11] и цифровой голографической микроскопии [12], причем для подтверждения гибели клеток исследуются изменения их морфологических параметров и проводятся тесты на целостность мембран.

Актуальной задачей является также определение пространственных распределений и времен жизни фотосенсибилизатора и синглетного кислорода в клетках, причем распределение фотосенсибилизатора может быть эффективно проконтролировано по сигналу его флуоресценции в видимой области спектра. В то же время единственным прямым методом детектирования синглетного кислорода является регистрация его фосфоресценции на длине волны около $1270 \mathrm{~nm}$, возникающей при переходе с синглетного возбужденного на триплетный основной уровень молекулы кислорода. Однако в силу запрещенности этого перехода сигнал фосфоресценции очень слабый и его регистрация, в 
особенности на клеточном уровне, представляет собой серьезную техническую задачу. Измерения проводятся с помощью высокочувствительных ИК ФЭУ в режиме счета фотонов с анализом по методу время-корреляционной спектроскопии $[13,14]$, либо с использованием высокочувствительных в ИК области современных матричных детекторов [15]. В этих измерениях необходимо иметь возможность надежно отделять сигнал фосфоресценции синглетного кислорода от возможной люминесценции других химических веществ в этом спектральном диапазоне. В первую очередь это касается излучения фосфоресценции фотосенсибилизатора, которое присутствует в широком спектральном диапазоне в ИК области, в том числе и в полосе фосфоресценции синглетного кислорода (см. например, [16,17]). Однако в таких многокомпонентных системах, как клеточные структуры in vitro, возможны и другие источники излучения, например питательная среда.

Настоящая работа посвящена исследованию спектральных характеристик питательной среды DMEM. Зарегистрирован спектр люминесценции среды в видимой и ближней ИК областях вплоть до $1350 \mathrm{~nm}$ при возбуждении на длинах волн 405 и $660 \mathrm{~nm}$, соответствующих основным полосам поглощения широко используемых в фотодинамической терапии фотосенсибилизаторов хлоринового ряда. Определены характеристические времена затухания люминесценции среды и продемонстрировано отсутствие пика люминесценции в области фосфоресценции синглетного кислорода вблизи $1270 \mathrm{~nm}$.

\section{Методика эксперимента и экспериментальная установка}

В экспериментах использовалась питательная среда DMEM производства Биолот (Россия), представляющая собой растворенную в очищенной воде смесь неорганических солей, аминокислот, витаминов, глюкозы, $\mathrm{L}$-глютамина и фенолового красного [18]. В среду добавлялось 10\% эмбриональной телячьей сыворотки (Биолот, Россия) и $0.1 \%$ гентамицина.

Спектр поглощения среды DMEM в области 220-800 nm измерялся с помощью спектрофлуориметра Флюорат 囚-02-Панорама (Люмэкс, Россия). Для исследования спектра люминесценции использовалась экспериментальная установка на базе монохроматора МДР-12 с дифракционной решеткой 600 lines $/ \mathrm{mm}$ и обратной дисперсией $4.8 \mathrm{~nm} / \mathrm{mm}[16]$; ширины входной и выходной щелей монохроматора устанавливались равными $2 \mathrm{~mm}$. Кварцевая кювета со средой помещалась вблизи входной щели монохроматора. Возбуждение люминесценции среды осуществлялось непрерывными полупроводниковыми лазерами на длинах волн 405 и $660 \mathrm{~nm}$ при плотностях мощности 2 и $2.7 \mathrm{~mW} / \mathrm{mm}^{2}$ соответственно. Рассеянное излучение лазера во втором порядке дифракции устранялось посредством отрезающих фильтров. Регистрация люминесценции в видимой и ближней ИК области вплоть до $1000 \mathrm{~nm}$ осуществлялась с помощью кремниевого фотодиода SPD-10, а в области 940-1350 nm - с помощью фотоэлектронного умножителя NIR-PMT H10330B-45 (Hamamatsu, Япония). Сшивка данных, полученных с помощью двух детекторов, проводилась по контрольным точкам в области перекрытия их диапазонов чувствительности. По полученным данным был построен полный спектр люминесценции среды DMEM в видимой и ближней ИК областях при возбуждении на длине волны $405 \mathrm{~nm}$ и в ближней ИК области при возбуждении на длине волны $660 \mathrm{~nm}$. Измерение времен жизни возбужденных состояний компонентов среды DMEM производилось при возбуждении среды импульсными лазерами на длинах волн 405 и $660 \mathrm{~nm}$ с длительностью импульса $100 \mathrm{~ns}$ методом время-корреляционной спектроскопии в режиме счета фотонов (TCSPC) с помощью измерительного модуля PicoHarp300 (PicoQuant, Германия). Во избежание фотовыцветания в каждой серии измерений использовался свежий раствор.

\section{Полученные результаты и их интерпретация}

На рис. 1 представлен спектр поглощения среды DMEM в диапазоне $220-800 \mathrm{~nm}$. Как видно из рис. 1, в спектре присутствуют ярко выраженные полосы поглощения с максимумами на длинах волн 240 и $270 \mathrm{~nm}$. Поскольку в составе исследуемой среды содержится смесь различных аминокислот [18], имеющих полосы поглощения в диапазоне от 230 до $300 \mathrm{~nm}$ [19], можно предположить, что эти пики поглощения в полученном спектре среды DMEM обусловлены именно наличием аминокислот. В спектре также наблюдается полоса поглощения с максимумом на длине волны $550 \mathrm{~nm}$. Для контроля рН в среде DMEM содержится индикатор краситель феноловый красный, который имеет два основных пика поглощения на длинах волн 420 и $550 \mathrm{~nm}$. Как известно, соотношение оптической плотности в этих двух полосах поглощения зависит от значения $\mathrm{pH}$ раствора. При значениях $\mathrm{pH}$ выше 7 пик на длине волны $550 \mathrm{~nm}$ значительно превалирует [20], при этом оптимальное значение $\mathrm{pH}$ для большинства клеток лежит в

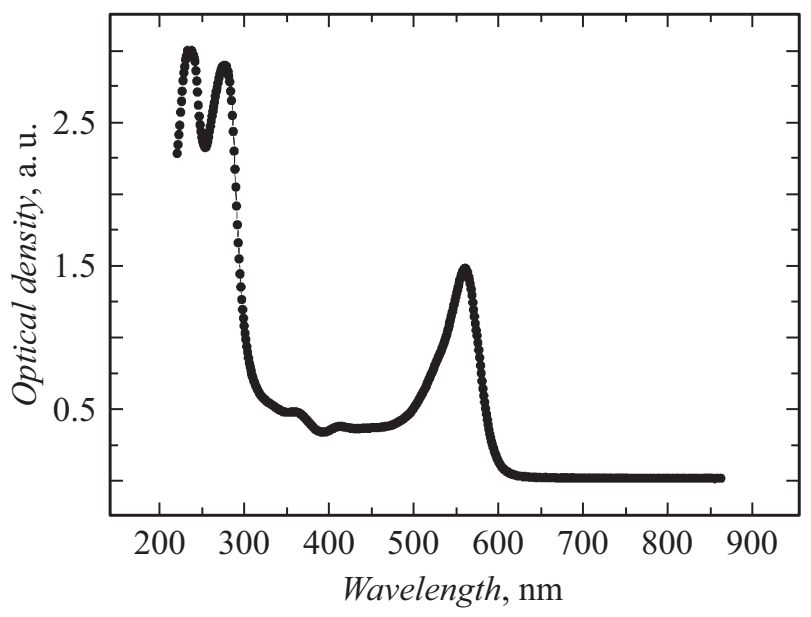

Рис. 1. Спектр поглощения питательной среды DMEM. 


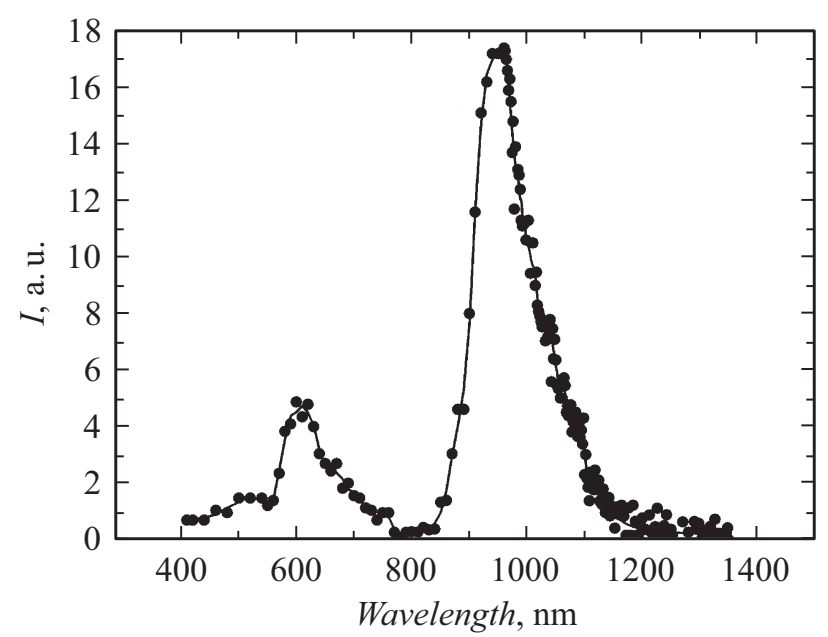

Рис. 2. Полный спектр люминесценции среды DMEM при возбуждении на длине волны $405 \mathrm{~nm}$.

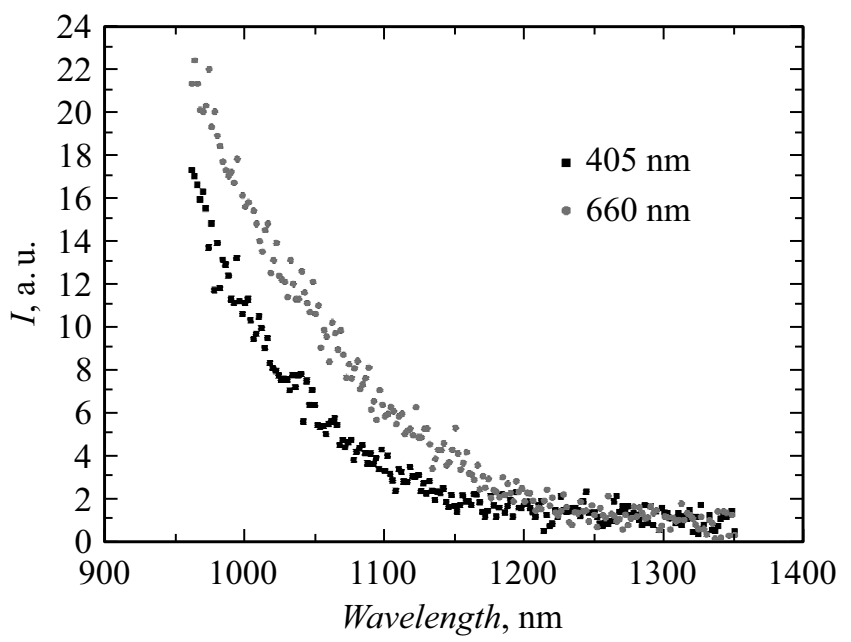

Рис. 3. Спектр люминесценции среды DMEM в ближней ИК области при возбуждении на длинах волн 405 и $660 \mathrm{~nm}$.

пределах 7.2-7.4 [5]. Поскольку при измерении спектра поглощения DMEM pH среды находился в данном диапазоне, можно предположить, что пик поглощения среды на длине волны $550 \mathrm{~nm}$ обусловлен наличием в составе среды индикатора фенолового красного.

На рис. 2 представлен полный спектр люминесценции среды DMEM, полученный при возбуждении на длине волны $405 \mathrm{~nm}$. В спектре присутствуют небольшой пик люминесценции с максимумом на длине волны $600 \mathrm{~nm}$ и ярко выраженный пик с максимумом на длине волны $970 \mathrm{~nm}$. Необходимо отметить, что этот пик люминесценции среды DMEM находится вблизи от полосы фосфоресценции фотосенсибилизаторов хлоринового ряда с максимумом на $940 \mathrm{~nm}$ [16]. На рис. 3 представлены спектры люминесценции в ближней ИК области (970-1350 nm) при возбуждении на длинах волн 405 и $660 \mathrm{~nm}$. Как видно из рисунка, общий вид спектров одинаков, разница в интенсивности сигналов люминесценции обусловлена разницей в коэффициентах
Характерные времена затухания люминесценции среды DMEM при возбуждении на длине волны $405 \mathrm{~mm}$

\begin{tabular}{c|c|c}
\hline $\begin{array}{c}\text { Длина волны } \\
\text { люминесценции, nm }\end{array}$ & $\begin{array}{c}\tau_{1}, \\
\mathrm{~ns}\end{array}$ & $\begin{array}{c}\tau_{2}, \\
\mathrm{~ns}\end{array}$ \\
\hline 940 & $0.85 \pm 0.07$ & $4.21 \pm 0.19$ \\
1000 & $0.94 \pm 0.08$ & $4.34 \pm 0.34$ \\
1100 & $0.79 \pm 0.03$ & $4.96 \pm 0.62$ \\
1270 & $0.62 \pm 0.03$ & $10.0 \pm 5.74$
\end{tabular}

поглощения на этих длинах волн, а также разной мощностью возбуждающего излучения. В области полосы фосфоресценции синглетного кислорода около $1270 \mathrm{~nm}$ пиков люминесценции не обнаружено.

Исследование времен жизни возбужденных состояний питательной среды DMEM проводилось посредством анализа кинетики сигналов люминесценции на разных длинах волн в ближней ИК области с высоким временным разрешением при возбуждении импульсным излучением лазера на длинах волн 405 и $660 \mathrm{~nm}$. На рис. 4 представлены экспериментальные кривые затухания сигнала люминесценции на нескольких длинах волн в диапазоне 940-1270 nm, полученные при возбуждении на длине волны $405 \mathrm{~nm}$. Как видно, ход кривых одинаков. Экспериментальные кривые хорошо аппроксимируются двухэкспоненциальной функцией вида

$$
I=A_{1} e^{-t / \tau_{1}}+A_{2} e^{-t / \tau_{2}}+y_{0} .
$$

С помощью этой аппроксимации были определены характерные времена затухания люминесценции (времена жизни возбужденных состояний), полученные значения приведены в таблице.

Как видно, времена затухания на разных длинах волн оказались равными в пределах погрешности измерений.

На рис. 5 представлена кинетика затухания сигнала люминесценции на длине волны $1270 \mathrm{~nm}$ при возбуждении на длине волны $660 \mathrm{~nm}$. Из анализа данной кривой были получены значения времен жизни

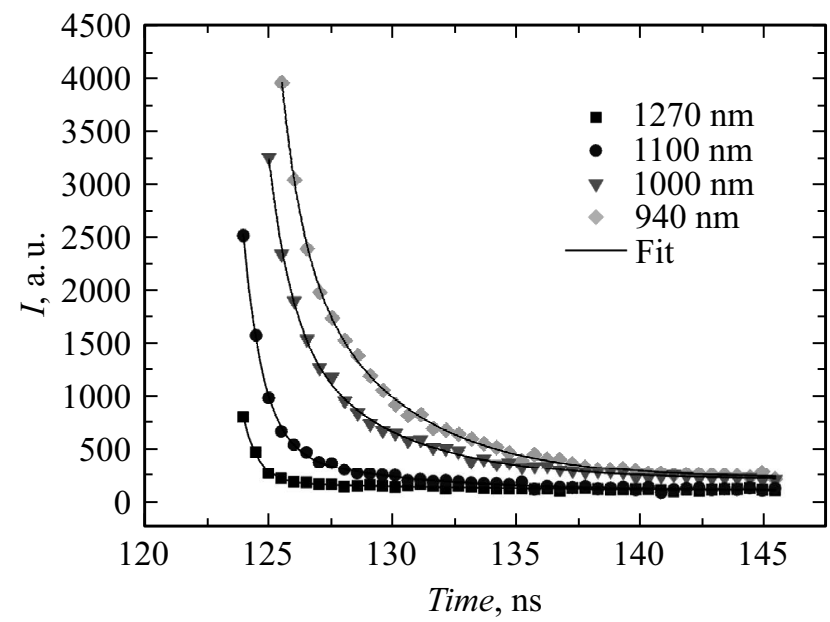

Рис. 4. Затухание сигнала люминесценции на длинах волн 940, 1000, 1100 и $1270 \mathrm{~nm}$ при возбуждении на длине волны $405 \mathrm{~nm}$. 


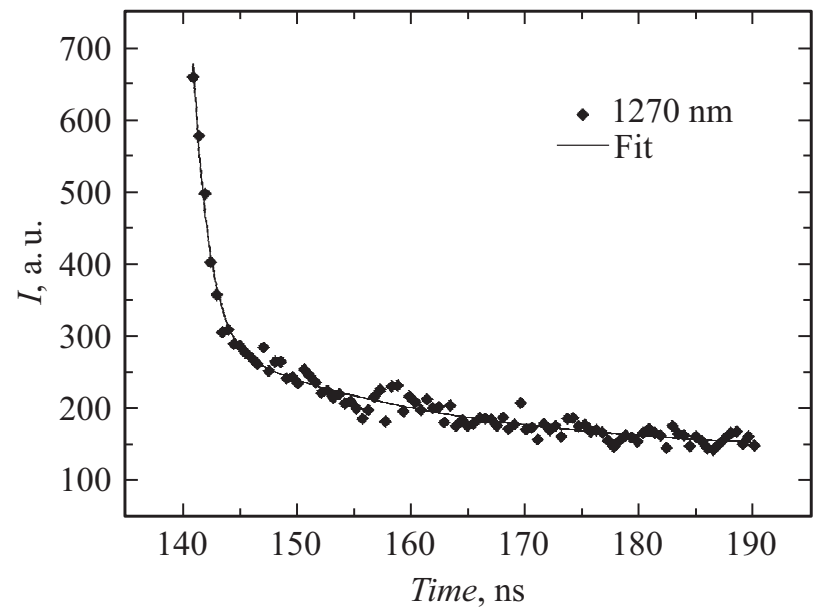

Рис. 5. Затухание сигнала люминесценции на длине волны $1270 \mathrm{~nm}$ при возбуждении на длине волны $660 \mathrm{~nm}$.

возбужденных состояний, равные $\tau_{1}=1.38 \pm 0.10 \mathrm{~ns}$ и $\tau_{2}=20.99 \pm 3.91 \mathrm{~ns}$. Полученные значения времен жизни возбужденных состояний среды DMEM находятся в наносекундном диапазоне и соответствуют разрешенным оптическим переходам между энергетическими уровнями молекул. Полученные значения являются приблизительными, поскольку для исследования кинетики сигнала люминесценции использовался лазер с длительностью импульса, существенно превышающей полученные значения времени жизни. Небольшое увеличение времени жизни на длине волны $1270 \mathrm{~nm}$ в обоих случаях можно объяснить большой ошибкой измерений при низком уровне сигнала люминесценции. Важным результатом является отсутствие долгоживущей люминесценции в области фосфоресценции синглетного кислорода вблизи $1270 \mathrm{~nm}$ с характерной формой кинетики в виде горба с нарастанием и затуханием в микросекундном диапазоне (см., например, [17]). Это подтверждает, что в условиях наших экспериментов при облучении среды DMEM не происходила генерация синглетного кислорода.

\section{Выводы}

Таким образом, в настоящей работе получен и проанализирован спектр поглощения питательной среды DMEM. Проведено исследование спектров люминесценции среды в видимой и ближней ИК областях при возбуждении на длине волны $405 \mathrm{~nm}$, и в ближней ИК области при возбуждении на $660 \mathrm{~nm}$. Зарегистрирован пик люминесценции среды DMEM, находящийся вблизи от полосы фосфоресценции фотосенсибилизаторов хлоринового ряда. Наличие люминесценции среды в этом диапазоне необходимо учитывать при проведении исследований, основанных на регистрации фосфоресценции фотосенсибилизаторов. Продемонстрировано отсутствие максимума люминесценции на длине волны фосфоресценции синглетного кислорода для обеих длин волн возбуждения. Получены кинетики затухания сигнала люминесценции на разных длинах волн для обоих режимов возбуждения. Продемонстрировано, что затухание сигнала люминесценции носит двухэкспоненциальный характер и определены характерные времена затухания. Полученные в настоящей работе результаты могут быть использованы при флуоресцентных исследованиях клеток in vitro, культивированных в питательной среде DMEM.

\section{Список литературы}

[1] Gospodarowicz D., Greenburg G., Bialecki H., Zetter B.R. // In Vitro. 1978. Vol. 14. N 1. P. 85-118.

[2] Reddy M.L.P., Divya V., Pavithran R. // Dalton Transactions. 2013. Vol. 42. N 43. P. 15249-15262.

[3] Zhang X., Zhang X., Yang B., Liu L., Hui J., Liu M., Chen Y., Wei Y. // RSC Advances. 2014. Vol. 4. N 20. P. 10060-10066.

[4] Leung B.O., Chou K.C. // Appl. Spectroscopy. 2011. Vol. 65. N 9. P. $967-980$.

[5] Arora M. // Mater. Methods. 2013. Vol. 3. P. 175.

[6] Shah S.J., Blumen S., Pitha-Rowe I., Kitareewan S., Freemantle S.J., Feng Q., Dmitrovsky E. // Molecular Cancer Therapeutics. 2008. Vol. 7. N 4. P. 905-914.

[7] Di Certo M.G., Batassa E.M., Casella I., Serafino A., Floridi A., Passananti C., Molinari P., Mattei E. // BMC Cell Biology. 2008. Vol. 9. N 1. P. 56.

[8] Kumar P., Bolden G., Arise K.K., Krazit S.T., Pandey K.N. // Bioscience Reports. 2009. Vol. 29. N 1. P. 57-70.

[9] Berezin M.Y., Achilefu S. // Chem. Rev. 2010. Vol. 110. N 5. P. 2641-2684.

[10] Stefflova K., Chen J., Zheng G. // Front Biosci. 2007. Vol. 12. N 12. P. 4709-4721.

[11] Manoil D., Filieri A., Gameiro C., Lange N., Schrenzel J., Wataha J.C., Bouillaguet S. // Photodiagnosis and Photodynamic Therapy. 2014. Vol. 11. N 3. P. 372-379.

[12] Belashov A.V., Zhikhoreva A.A., Belyaeva T.N., Kornilova E.S., Petrov N.V., Salova A.V., Semenova I.V., Vasyutinskii O.S. // Opt. Lett. 2016. Vol. 41. N 21. P. 5035-5038.

[13] Kim I.W., Park J.M., Roh Y.J., Kim J.H., Choi M.G., Hasan T. // J. Photochem. Photobiol. B: Biology. 2016. Vol. 159. P. 14-23.

[14] Hackbarth S., Schlothauer J., Preuß A., Röder B. // J. Photochem. Photobiol. B: Biology. 2010. Vol. 98. N 3. P. $173-179$.

[15] Scholz M., Dědic R., Valenta J., Breitenbach T., Hála J. // Photochem. Photobiolog. Sci. 2014. Vol. 13. N 8. P. 1203-1212.

[16] Belik V.P., Gadzhiev I.M., Petrenko M.V., Petrov M.A., Semenova I.V., Vasyutinskii O.S. // Chem. Phys. Lett. 2016. Vol. 665. P. 127-130.

[17] Belik V.P., Gadzhiev I.M., Semenova I.V., Vasyutinskii O.S. // Spectrochim. Acta. Part A: Molecular and Biomolecular Spectroscopy. 2017. Vol. 178. P. 181-184.

[18] Химический состав питательной среды DMEM производства Биолот [Электронный ресурс] : фармацевтическая компания OOO „БиолоТ“. URL: http://www.biolot.ru/

[19] Луnпа Х. Основы гистохимии. М.: Мир, 1980. 343 с.

[20] Юинг Г. Инструментальные методы химического анализа / Пер с англ. М.: Мир, 1989. С. 82. 